\title{
WATER DISINFECTION WITH ADVANCED METHODS: SUCCESSIVE AND HYBRID APPLICATION OF ANTIBACTERIAL COLUMN WITH SILVER, ULTRASOUND AND UV RADIATION
}

\author{
GEMICI, B. T. ${ }^{1}-$ KAREL, F. B. ${ }^{2^{*}}-$ KARAER, F. ${ }^{2}-$ KOPARAL, A. S. ${ }^{2}$ \\ ${ }^{I}$ Department of Environmental Engineering, Bartın University, Bartın, Turkey \\ ${ }^{2}$ Department of Environmental Engineering, Anadolu University, Eskisehir, Turkey \\ *Corresponding author \\ email:fbayrakci@anadolu.edu.tr \\ (Received 28 $8^{\text {th }}$ Mar 2018; accepted 20 $0^{\text {th }}$ Jun 2018)
}

\begin{abstract}
The disinfection process is of great importance to the water supply to prevent diseases spread by water. Due to its negative impacts on human health, the number of studies conducted on disinfection systems alternative to chlorination and similar traditional methods has been increased. Successive and hybrid systems that are highly efficient in inactivating the pathogenic microorganisms that may be present in water are being developed. In this study, the disinfection efficiency of the antibacterial filled column, ultrasonic reactor and UV reactor that we developed was increased by the successive and hybrid usage of the methods when Escherichia coli bacteria were used to detect the disinfection efficiency of the systems. In single disinfection studies, bacterial inactivation efficiency occurred in UV process was higher than antibacterial column and also, efficiency occurred in antibacterial column was higher than ultrasonic reactor. Triple hybrid usage of these systems resulted in an $8 \log$ microbial inactivation reducing single treatment disadvantages of these systems. Furthermore, the flow speed and temperature effect were examined during the studies, and it was observed that the temperature had a positive effect on the hybrid system.
\end{abstract}

Keywords: bacterial inactivation, ultrasound, silver, ultraviolet radiation

\section{Introduction}

Obtaining safe drinking and usage water has been increasingly gaining importance today. The fecal microorganisms that contaminate water generally originate from infected or disease carrying animal and human wastes. When water is contaminated with fecal matter, the disinfection procedure required to remove the microbial load is very important. Chlorination, ozone, ultraviolet radiation (UV), filtration and other methods are widely used for disinfection at the water distribution source. Choosing the right disinfection method is important for achieving the most effective microbial removal in water. The main factors affecting the choice of disinfection method are the efficiency, cost, applicability, pilot study requirement and side effects. The disinfection efficiency is determined by the ability of the method to inactivate the selected microorganisms to the target level. The disinfection method must be practical; and its handling, storage and production/application in the field as well as its monitoring and control must be simple. It must also achieve disinfection targets. The disinfectant should not create a toxic effect on aquatic life, it should not be transported to or bioaccumulate in nutrients, and it should not be transformed into or form carcinogenic, mutagenic or toxic substances (Liviac et al., 2010). Therefore, the side effects of the system used must be researched. When all of these elements come 
together, a compelling argument can be made for using methods such as disinfection with ultrasound and metal ions as an alternative to conventional techniques when these new systems are used successively as hybrids.

Metal ions such as $\mathrm{Hg}, \mathrm{Au}, \mathrm{Ag}, \mathrm{Pb}$ and $\mathrm{Cu}$ affect living organisms as disinfecting substances (Blanc et al., 2005). Metal ions are effective for the inactivation of bacteria (Fauss et al., 2014), fungi (Das et al., 2013) and viruses (De Gusseme et al., 2011), even at low concentrations. Metal ions inhibit the growth of some algae and fungi. A review of the literature (Chang et al., 2008; De Gusseme et al., 2011; Das et al., 2013; Fauss et al., 2014) shows that the Ag ion has often been used in antibacterial material production (Srinivasan et al., 2013) and water disinfection studies because it is nontoxic and effective for human health, even at low concentrations compared to other metal ions.

It is possible to kill the cells of microbial populations through ultrasound. The bactericidal effect of ultrasound is related to cavitation (Declerck et al., 2010). The formation of bubbles during cavitation usually kills the microbial cells (Naddeo et al., 2014). Small, high energy gas filled bubbles are formed during cavitation. The ultrasound process causes the microscopic bubbles to explode and a mechanical shock occurs (Rutala et al., 2007). High temperature $\left(5500^{\circ} \mathrm{C}\right)$ and pressure $(50 \mathrm{Mpa})$ points are formed when the molecules around the bubbles collide with each other during explosions (Leighton, 2007). Fragmentation occurs after the destruction of structural and functional units in the cell (Skauen, 1976). The cavitation bubbles blow up when the ultrasound is applied, and $\mathrm{OH}^{-}$and $\mathrm{H}+$ reactive radicals are produced in the liquid media (Birkin et al., 2001). $\mathrm{H}_{2} \mathrm{O}_{2}$ (hydrogen peroxide) is formed when these radicals react with oxygen. The intense bubble formation prevents temperature and pressure alterations and causes DNA lysis, cell membrane disintegration and cell wall damage when the free radicals are formed (Vasilyak, 2010).

Since the 1900s, radiation emitted from an ultraviolet light source has been used for the disinfection of water sources (Choi and Choi, 2010). UV radiation, initially used for high quality water supplies, has gained importance in recent years in the treatment of waste water (Copperwhite et al., 2012; Nelson et al., 2013). It was determined that ultraviolet radiation at sufficient dosages may be used as a bactericide and virucide without forming any toxic compounds (Xu et al., 2009; Oguma et al., 2013). Radiation at a wavelength of $254 \mathrm{~nm}$ prevents cell reproduction when it passes through the cell membrane of the microorganism, leading to its death (Rincon and Pulgarin, 2004). The disinfection efficiency of UV radiation depends on the turbidity of the water (Bergmann et al., 2002). Therefore, a pre-distillation process such as filtration is needed when the organic content of the water is high and when it is turbid (Winward et al., 2008; Abd-Elmaksoud et al., 2013).

In the disinfection studies that were conducted using ultraviolet radiation, ultrasound and metal ions, it was possible to increase the bacterial inactivation efficiency and remove its disadvantages when successive and hybrid methods were used (Summerfelt et al., 2009; Wu et al., 2011; Zhu et al., 2014). Amirsardari, Yu and Williams found that trihalomethanes were decreased by $90 \%$ and halides were decreased by $98 \%$ when ozonation was used as a pre-treatment method along with UV radiation (Amirsardari et al., 2001). Butkus et al. (2005) determined that one more log removal was obtained compared to single UV radiation application in the inactivation of MS-2 coliphage viruses at $10^{9} \mathrm{PFU} / \mathrm{mL}$ concentration when UV radiation was used. Naddeo et al. (2009) determined that the disinfection efficiency of the US-UV hybrid 
system was approximately $96 \%$ while the disinfection efficiency of the UV system alone was approximately $80 \%$ in the total coliform and E. coli disinfection studies that were conducted using pilot-scaled ultrasonic and UV reactors.

This study aims to develop alternative water disinfection systems with the goal of recovering disadvantages present in conventional water disinfection methods and increasing the efficiency of the disinfection. Except for conventional disinfection methods, the bacterial inactivation efficiencies of UV radiation, ultrasound and $\mathrm{Ag}^{+}$ ion adulterated antibacterial column methods were examined with the goal of achieving optimal water hygiene standards. The disinfection efficiencies of these methods in dual ((Ag+ US, $\mathrm{Ag}+\mathrm{UV}, \mathrm{US}+\mathrm{UV})$ and triple $(\mathrm{Ag}+\mathrm{US}+\mathrm{UV})$ successive systems were determined. We concluded that the disinfection efficiency was increased when successive systems were applied.

\section{Materials and methods}

This research was conducted in Department of Environmental Engineering, Anadolu University, Eskisehir, Turkey.

In this study, the disinfection efficiencies of antibacterial filled columns, ultrasonic (US) reactors and UV reactors were determined under continuous flow conditions. The inactivation of Escherichia coli bacteria was examined after single (Ag, US and $\mathrm{UV}$ ), dual (Ag+US, Ag+UV and US+UV) and triple (Ag+US+UV) system disinfection.

\section{Water disinfection with the antibacterial filled column}

Two mm bead-shaped antibacterial filling material was used for water disinfection in the antibacterial filled column. Brick dust was used as the primary body material to which $25 \%$ antibacterial powder was added. The filling materials were then baked at $800{ }^{\circ} \mathrm{C}$. Antibacterial powder (ABP) has an antibacterial effect due to the presence of silver. The calcium and phosphate based body releases the silver in a controlled manner. The reactor column that was used in this study had a height of $30 \mathrm{~cm}$ and a diameter of $2 \mathrm{~cm}$.

Inductively Coupled Plasma Optical Emission Spectroscopy (ICP-OES, Varian 720) was used to measure the silver concentrations in treated water to control silver released from $\mathrm{ABP}$ because hesitation of silver usage in water has increasing for human health recently. In order to show silver concentration released from ABP is under safe limit, measurements were taken after subjecting the study solution through the antibacterial filled column at different flow rates. The study solutions were put through the reactor one time at different continuous flow rates: $5 \mathrm{~mL} / \mathrm{min}, 25 \mathrm{~mL} / \mathrm{min}$, $50 \mathrm{~mL} / \mathrm{min}$ and $100 \mathrm{~mL} / \mathrm{min}$.

\section{Water disinfection with the ultrasonic reactor}

An ultrasonic reactor that generates sound at a frequency of $40 \mathrm{kHz}$ referred lowfrequency ultrasound was used in the ultrasound disinfection procedure. The ultrasonic reactor was designed by us and has a diameter of approximately $60 \mathrm{~mm}$ and a width of $40 \mathrm{~mm}$. There were transducers at two sides of the reactor. 100 watts of power was applied to the system. The disinfection studies were conducted at the 5 $\mathrm{mL} / \mathrm{min}, 25 \mathrm{~mL} / \mathrm{min}, 50 \mathrm{~mL} / \mathrm{min}$ and $100 \mathrm{~mL} / \mathrm{min}$. flow rates. 


\section{Water disinfection with the $U V$ reactor}

The UV disinfection column that was used for inactivating the microorganisms in this study had a diameter of $4.6 \mathrm{~cm}$ and a length of $25 \mathrm{~cm}$. The UV lamp that was used here (Philips TUV $8 \mathrm{~W}$ UVC) had a wavelength of approximately $254 \mathrm{~nm}$. The studies carried out in the continuous system using $1.3 \mathrm{~L} / \mathrm{min}$ and $2.6 \mathrm{~L} / \mathrm{min}$ flow rates.

\section{Water disinfection with successive systems}

Water disinfection with successive systems was carried out with the goal of removing disadvantages of the disinfection methods and observing the synergetic effects of these methods. The antibacterial filled column, the ultrasonic reactor and the UV reactor were successively used as dual and triple systems in the successive disinfection studies. The triple hybrid disinfection system yielded the best results and was conducted at $40{ }^{\circ} \mathrm{C}$ as well as ambient temperature $\left(25^{\circ} \mathrm{C}\right)$. The goal was to determine the temperature effect.

The disinfection studies where the antibacterial filled column and ultrasonic reactor were successively used were conducted at a $5 \mathrm{~mL} / \mathrm{min}$ flow rate for the antibacterial filled column and a $25 \mathrm{~mL} / \mathrm{min}$ flow rate for the ultrasonic reactor.

The disinfection studies where the ultrasonic reactor and UV reactor were successively used were conducted at a $5 \mathrm{~mL} / \mathrm{min}$ flow rate for the ultrasonic reactor and a $2.6 \mathrm{~mL} / \mathrm{min}$ flow rate for the UV reactor.

The disinfection study where the antibacterial filled column, ultrasonic reactor and UV reactor were used as a triple hybrid system was conducted using a $5 \times 10^{8} / \mathrm{mL}$ bacterial concentration. The flow rates for the antibacterial filled column and the ultrasonic reactor were $100 \mathrm{~mL} / \mathrm{min}$, and the flow rates for the UV reactor were $1.3 \mathrm{~L} / \mathrm{min}$ and $2.6 \mathrm{~L} / \mathrm{min}$. The study was performed at a $2.6 \mathrm{~L} / \mathrm{min}$ at a flow rate under $40{ }^{\circ} \mathrm{C}$.

\section{Microbiologic studies}

The solution to be used for the disinfection studies was prepared by adding Escherichia coli bacteria to sterilized distilled water at the desired concentrations. The desired initial bacterial concentrations were obtained by making necessary dilutions from a bacteria culture that was kept for 1 day at $37^{\circ} \mathrm{C}$. The samples were cultivated in plate count agar (PCA, Merck KGgA, Germany) media and were incubated for 1 day at $37^{\circ} \mathrm{C}$. The microbiologic studies were conducted at ambient temperature inside sterile cabinets (Heraeus KSP- 18 Class II). After incubation, the efficiency of the disinfection systems was determined by counting the colonies. It was assumed that bacteria that were alive equaled a colony in solid media.

The bacterial concentration of initial and effluent water was determined with a simple and well-known plate count method during all disinfection studies using serial dilution of the samples. $1 \mathrm{~mL}$ aliquot was taken from treated water and un treated water according to desired time interval depending operation parameters (flow rate, hydraulic retention time or disinfection period). The bacterial concentrations of aliquot taken from system were obtained by making necessary dilutions $(10 \times, 100 \times$ and $1000 \times$ dilutions) transferring $9 \mathrm{~mL}$ sterilized water gradually. $150 \mu \mathrm{L}$ samples taken from each dilution was inoculated on PCA solid media, and the plates were incubated at $37^{\circ} \mathrm{C}$ for $18-24 \mathrm{~h}$. The bacterial concentration of each samples was calculated using viable cells grown in PCA plates and $150 \mu \mathrm{L}$ sampled volume as colony forming unit per sample volume expressed $\mathrm{mL}(\mathrm{CFU} / \mathrm{mL})$. 
The results of microbiological studies were expressed as average of three independent experiments with error bar using standard deviation (SD). Each experiment was performed with three parallels. Statistical significance of the difference of the counted bacteria in in plate count agar among each trials was determined by analysis of variance (ANOVA) using one-way post hoc statistical test. In order to show reliability of measurement, $p$ value obtained from one-way ANOVA test was given for each disinfection study.

\section{Results and discussion}

\section{The disinfection efficiency with the antibacterial filled column}

The disinfection procedure was conducted at a $1 \times 10^{5} \mathrm{CFU} / \mathrm{mL}$ bacterial concentration using different flow rates with the goal of determining the efficiency of the antibacterial filled column. The experimental results are given in Figure 1.

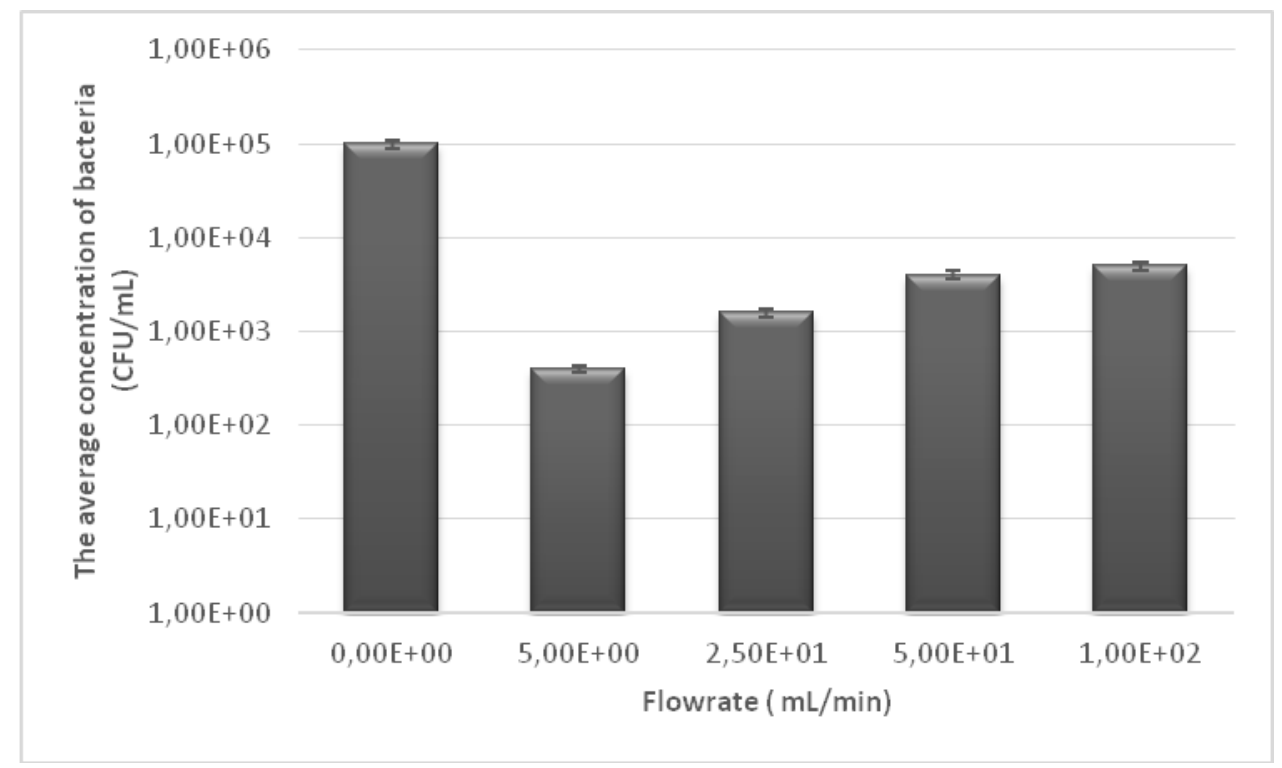

Figure 1. The effect of different flow rates on bacteria removal at a $1 \times 10^{5} \mathrm{CFU} / \mathrm{mL}$ initial bacterial concentration in the antibacterial filled column ( $p$ value was calculated as

0.0000000003 using one-way ANOVA test. This value showed that there is no significant difference of each measurements among each three disinfection experiment because $p<0.01$ )

The best bacteria removal was achieved at the $5 \mathrm{~mL} / \mathrm{min}$ flow rate. As the contact time with the active matter increases with a decrease in flow rate, it is expected that the bacterial inactivation rate also increases. These results are seen in Figure 1. 2 log bacterial inactivation was achieved for the $5 \mathrm{~mL} / \mathrm{min}$ flow rate. The silver concentrations of the study solutions subjected through the antibacterial filled column in a continuous system at different flow rates are given in Figure 2.

It was observed that the amount of silver present in the samples at the $5 \mathrm{~mL} / \mathrm{min}$ flow rate was greater than that at other flow rates, however $5 \mathrm{~mL} / \mathrm{min}$ was the lowest flow rate used in the study. The silver concentration at $5 \mathrm{~mL} / \mathrm{min}$ was determined to be $74 \mu \mathrm{g} / \mathrm{L}$. 


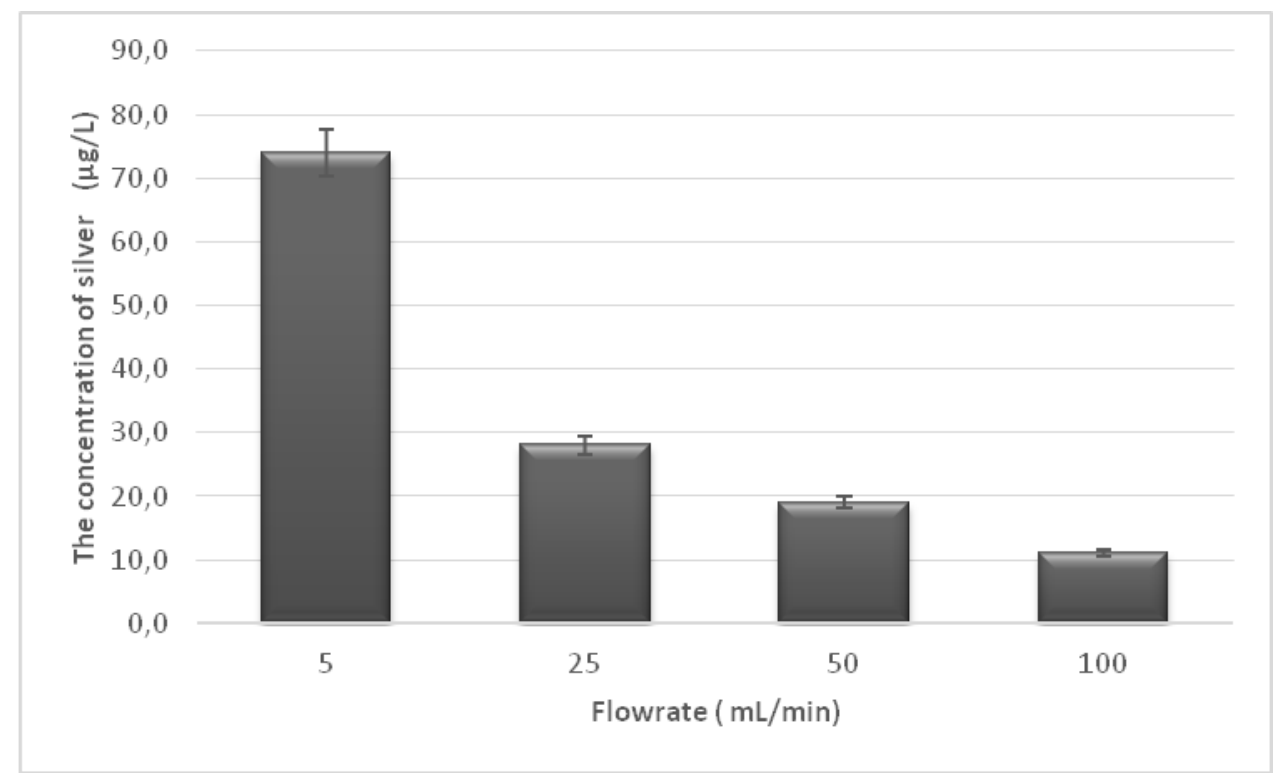

Figure 2. The silver amounts that are released to study the solution of different flow rates in the antibacterial filled column disinfection procedure (DL: $0.35 \mu \mathrm{g} / \mathrm{L}, \mathrm{RSD}: 5 \%$ and $R^{2}: 0,9967$ of ICP-OES calibration)

Silver ions have the highest level of antimicrobial activity of all the heavy metals and its bacterial inactivation mechanism is well known in the literature. Our study demonstrated that disinfection process conducted with antibacterial filled column achieved sufficient inactivation ratio using silver ions released to water from filling materials surface.

Although, there is no unique or rigid safe limit of silver ion concentration allowed in water according to health and environmental organization, number of studies focused on silver toxicity has been increasing in literature to find out safe limit of silver used in potential implications for human health and the environment (Marambio-Jones and Hoek, 2010). These studies have showed that silver can be present in metallic silver, silver salts (generally silver sulphate), silver complexes and nano-sized silver. Also, researcher has reported silver nano particle is more toxic to fish, algae, some plants, fungi and mammalian cells due to nanosized effect than silver salts compounds (Panyala et al., 2008). Marambio-Jones and Hoek reported toxiccity concentraions of silver between $50 \mu \mathrm{g} / \mathrm{mL}-100 \mu \mathrm{g} / \mathrm{mL}$ among rewied reserchs depending toxicity organisms and silver form presented in water.

The results of disinfection studies and ICP-OES analyses showed that increasing hydraulic retention time affected directly disinfection efficiency because silver ion amount released to water increased with lowering water flow rate. ICP-OES measurement showed that silver concentration released from ABT to water was under toxicity level reported in previous studies and released silver concentration could be controlled increasing flowrate. In order to achieve powerful bacterial disinfection in antibacterial column, silver ion concentration should be increased in water according to water and health regulation for silver amount of water to avoid its environmental risks. However, there are two possible problems in the case of demanding more silver concentration to achieve adequate disinfection efficiency for strength microorganisms. These are the increasing cost of silver added to system and increasing silver amount in 
the human bodies consuming the water disinfected with silver due to bioaccumulation. Our study indicates that innovative successive and hybrid disinfection process conducted with ultrasound and UV can be used in order to escape these problems.

\section{The disinfection efficiency of the ultrasonic reactor}

The disinfection procedure was conducted using a $1 \times 10^{5} \mathrm{CFU} / \mathrm{mL}$ bacterial concentration subjected to a $40 \mathrm{kHz}$ ultrasonic frequency with the goal of determining the efficiency of the ultrasonic reactor. The results obtained using different flow rates through the ultrasonic reactor are given in Figure 3.

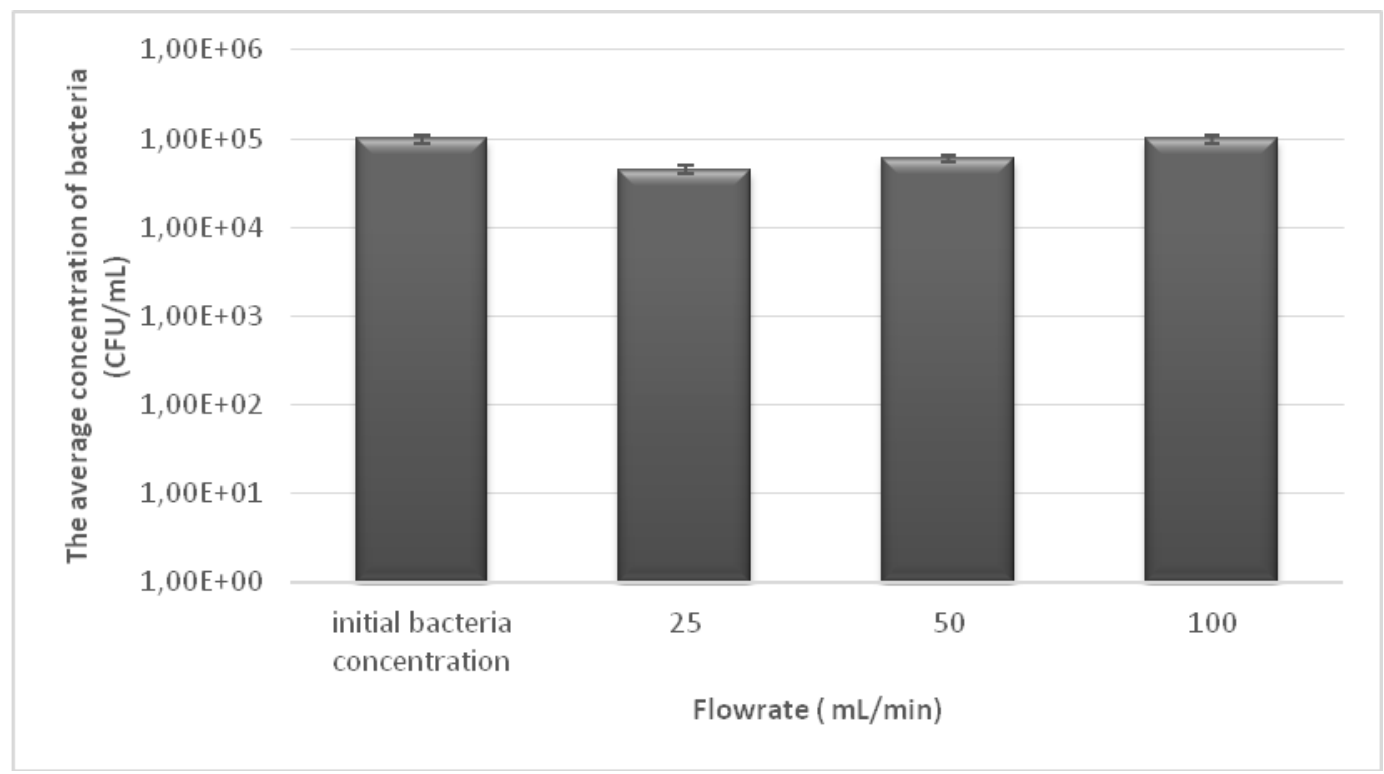

Figure 3. The effect of bacteria removal at a $1 \times 10^{5} \mathrm{CFU} / \mathrm{mL}$ initial bacterial concentration in ultrasonic reactors at different flow rates ( $p$ value was calculated as 0.000020158 using oneway ANOVA test. This value showed that there is no significant difference of each measurements among each three independent disinfection experiment of three treatment conditions because $p<0.01$ )

In the ultrasonic reactor, $0.5 \log$ bacterial inactivation was achieved at the $25 \mathrm{~mL} / \mathrm{min}$ flow rate. Bacterial inactivation increased with a decrease in flow rate. The result of the ultrasonic disinfection studies showed that ultrasound had no significant effect on inactivation of Escherichia coli in the case of single application. The mechanical effects of low-frequency ultrasound leading to cell membrane disruption of bacteria were probably insufficient for the inactivation of Escherichia coli (Joyce et al., 2003). It was stated that higher bacterial inactivation required higher power supply for ultrasound usage aiming disinfection in literature (Mason et al., 2003). In order to recover this disadvantages of ultrasound for water disinfection various ultrasonic reactor was produced with different frequency, power supply and different configuration. Cerecedo et al. (2018) conducted a disinfection study using rotor-stator device for water disinfection based on hydrodynamic cavitation and they reported that the water was infected with $E$. coli and E. faecalis with initial concentrations in the range $5 \times 10^{2}-$ $1.2 \times 10^{6} \mathrm{CFU} / \mathrm{ml}$ due to mechanical cavitation's cell membrane disruption. 


\section{The disinfection efficiency of the $U V$ reactor}

Escherichia coli disinfection was conducted using an initial bacteria concentration of $3 \times 10^{8} \mathrm{CFU} / \mathrm{mL}$ with the aim of determining the efficiency of the UV reactor. The results obtained from the UV disinfection procedure conducted at different flow rates are given in Figure 4. A 5 log bacterial inactivation was achieved for both of the flow rates used in the studies. The UV reactor effectively disinfected very high initial bacteria concentrations. In single UV disinfection studies, bacterial inactivation efficiency was significantly higher than antibacterial column and ultrasonic reactor.

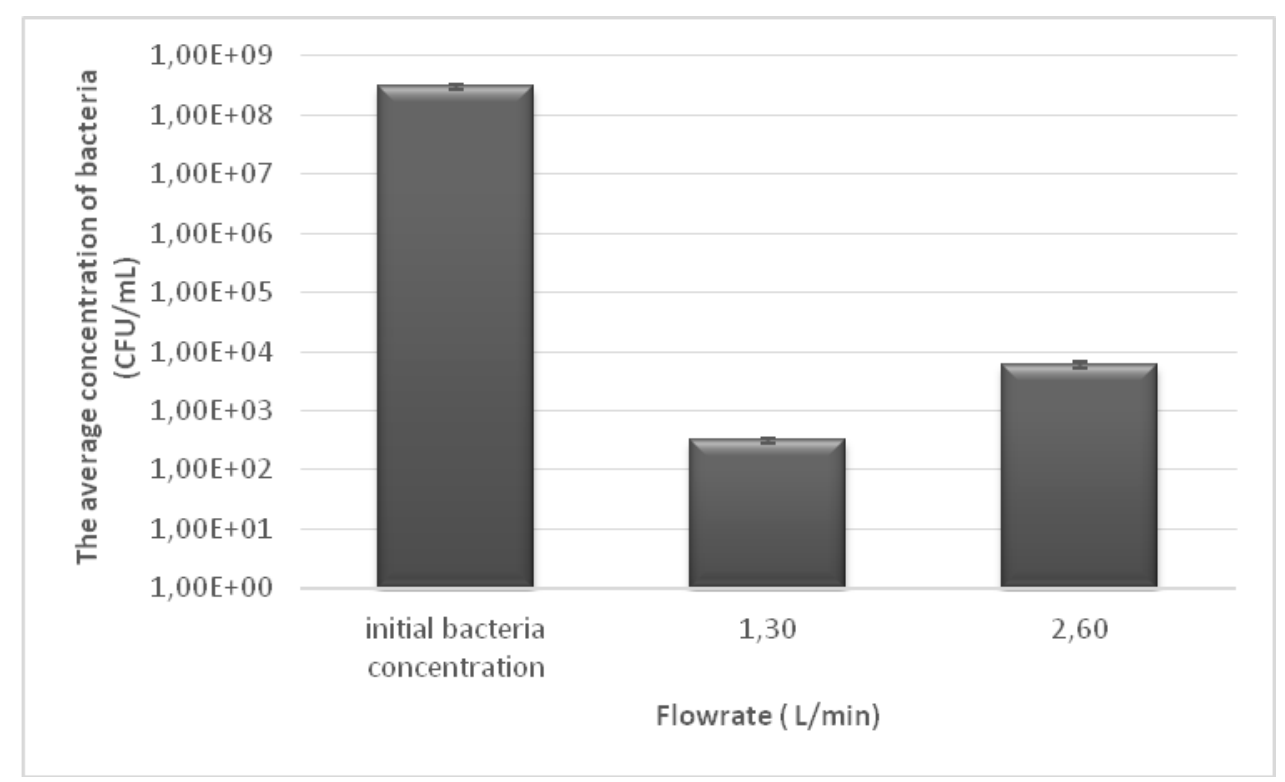

Figure 4. The effect of bacteria removal at a $3 \times 10^{8} \mathrm{CFU} / \mathrm{mL}$ initial bacterial concentration in the UV reactor at different flow rates ( $p$ value was calculated as 0.000000070 using one-way ANOVA test. This value showed that there is no significant difference of each measurements among each three independent disinfection experiment of two treatment conditions because

$$
p<0.01)
$$

\section{The disinfection efficiency of successive systems}

The results obtained from the studies conducted with the goal of determining the effectiveness of the dual antibacterial filled column and ultrasonic systems are given in Figure 5.

The silver ions were more evenly distributed inside the liquid media in the ultrasonic systems. Therefore, the efficiency of the disinfection was increased by providing continuous silver-bacteria contact inside the liquid media. Another factor increasing the efficiency of the disinfection was that the ultrasound damaged the cell membrane of the bacteria and the silver ions are much more effective when the cell membrane is damaged. In the studies conducted using the ultrasonic system after the antibacterial filled column all of the bacteria available in the media were inactivated and $\log 5$ inactivation was achieved. 


$$
-4675 \text { - }
$$

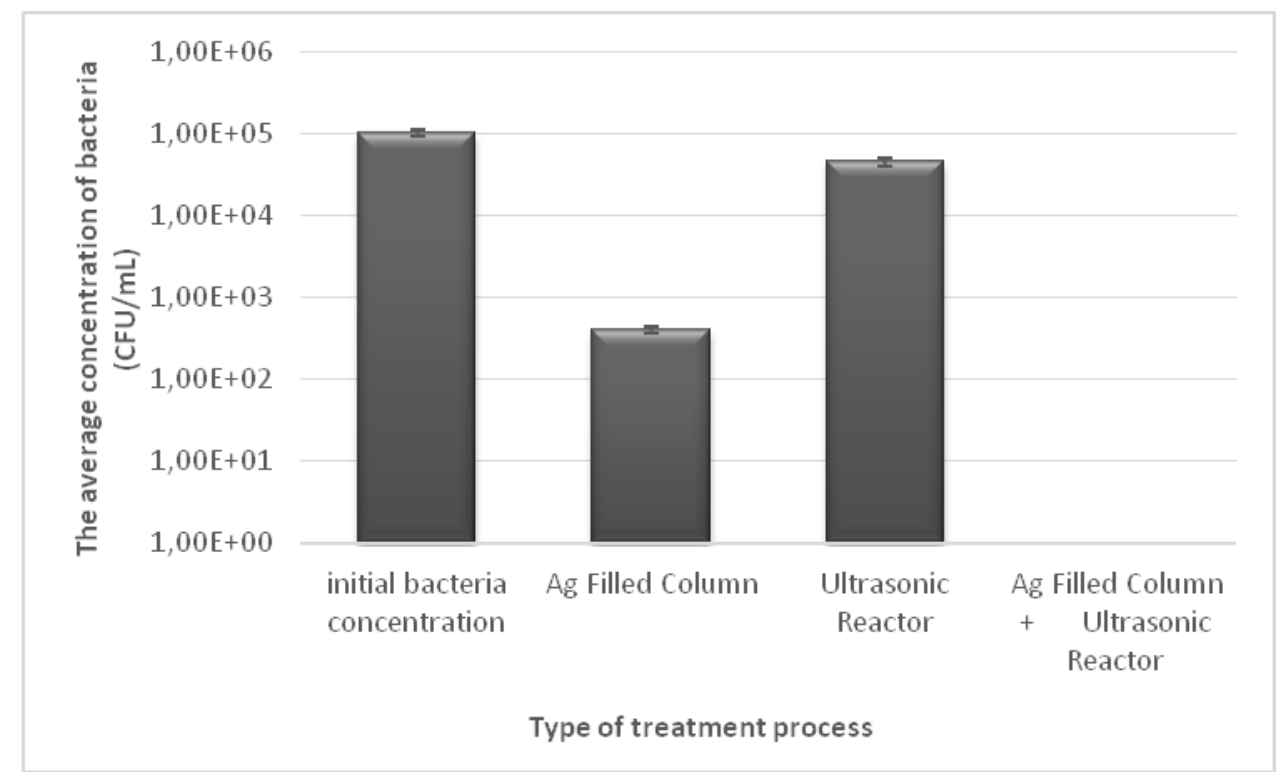

Figure 5. The effect of the antibacterial filled column and ultrasonic system together at a $10^{5}$ $C F U / m L$ initial bacterial concentration ( $p$ value was calculated as 0.0005173 using one-way ANOVA test. This value showed that there is no significant difference of each measurements among each three independent disinfection experiment of three treatment conditions because

$$
p<0.01)
$$

The results of the studies conducted with the goal of determining the efficiency of the dual system where the ultrasound reactor and the UV reactor were successively used are given in Figure 6.

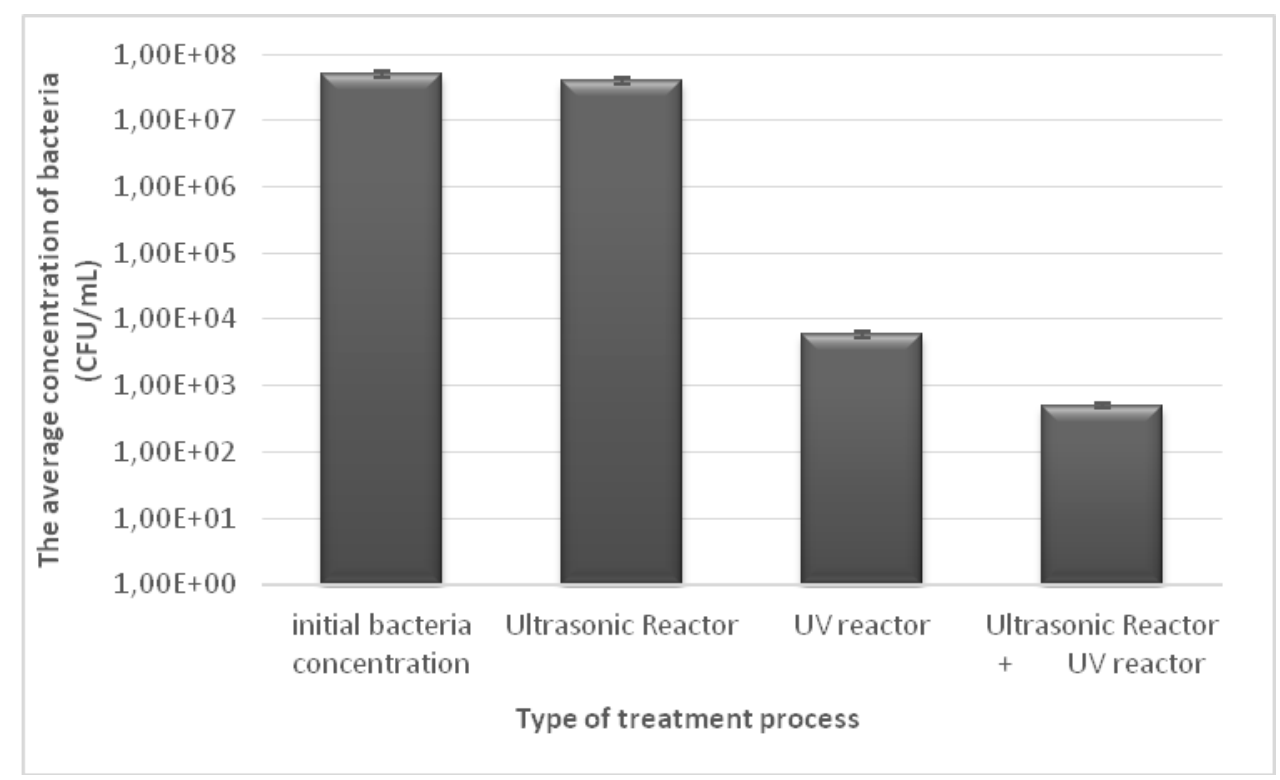

Figure 6. The effect of the UV and ultrasonic system together at a $1 \times 10^{8} \mathrm{CFU} / \mathrm{mL}$ initial bacterial concentration ( $p$ value was calculated as 0.000000070 using one-way ANOVA test. This value showed that there is no significant difference of each measurements among each three independent disinfection experiment of three treatment conditions because $p<0.01$ ) 
This study revealed that the dual ultrasonic and UV reactor system had a stronger disinfection effect than when each was used alone. When these systems were used together, a $6 \log$ bacterial inactivation was achieved. The study using the antibacterial material-filled column and the UV reactor together aimed to examine the disinfection efficiency of the dual system. The results obtained from the studies are given in Figure 7. When the antibacterial filled column and the UV reactor were used together the disinfection efficiencies increased. 7 log bacterial inactivation was achieved using this system successively.

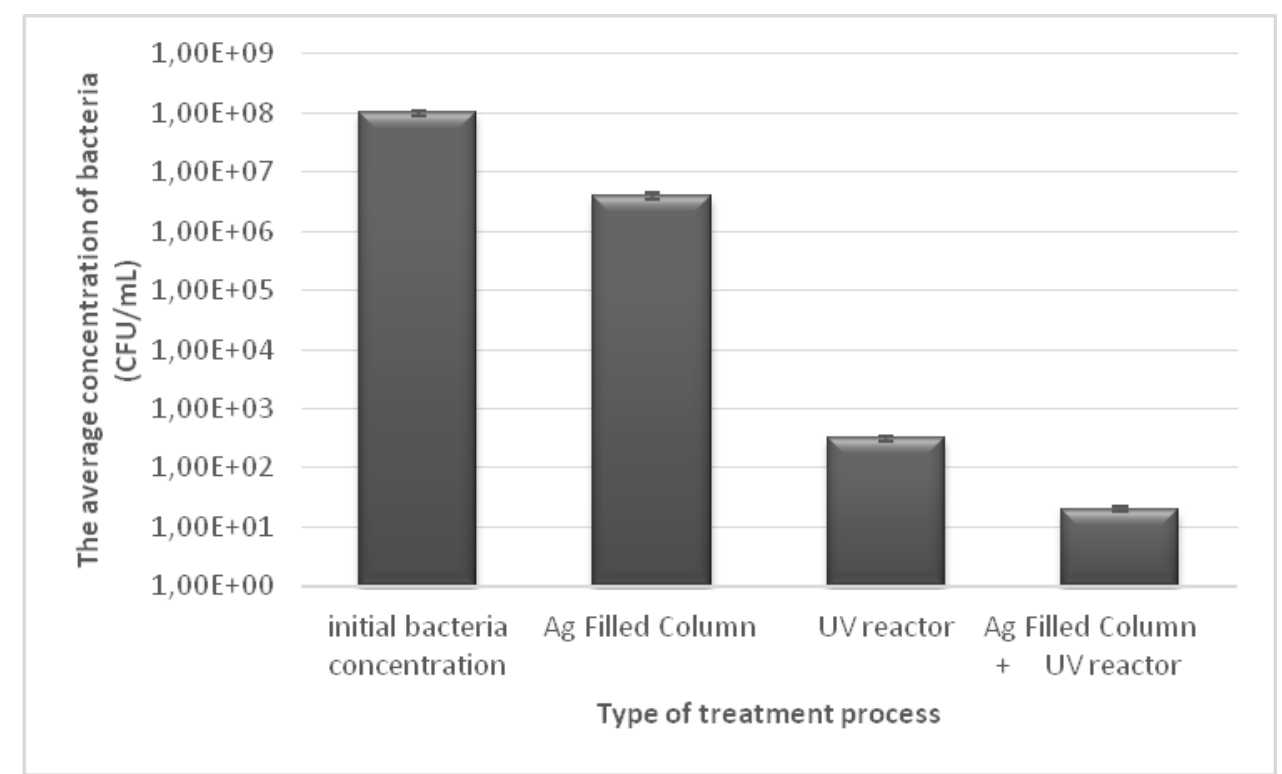

Figure 7. The successive effect of antibacterial filled column and UV reactor at a $1 \times 10^{8}$ $C F U / m L$ initial bacterial concentration ( $p$ value was calculated as 0.000000016 using one-way ANOVA test. This value showed that there is no significant difference of each measurements among each three independent disinfection experiment of three treatment conditions because $p<0.01)$

These result demonstrated that successive application of three systems could be successfully performed for Escherichia coli disinfection reducing total silver amount released to the water related and increasing mechanical effects of low frequency ultrasound. Also, the efficiency of UV treatment was improved with synergistic effects of ultrasound and silver ion. It was observed that the use of successive systems increases the efficiency of disinfection. The effectiveness of each disinfection system increases when the bacteria has sufficient contact with the disinfectants. The ultrasound reactor contributed to the effectiveness by decreasing the shielding effect in the bacteria. The Ag ion was better distributed inside the system when the ultrasound reactor was used and the disinfection effectiveness of the systems when used together was higher.

\section{The disinfection efficiency of triple successive systems}

Triple hybrid studies were conducted using the antibacterial filled column, the ultrasound reactor and the UV reactor together. The results obtained from the study are given in Figure 8 and post hoc statistic test results of final disinfection study were summarized in Table 1. 


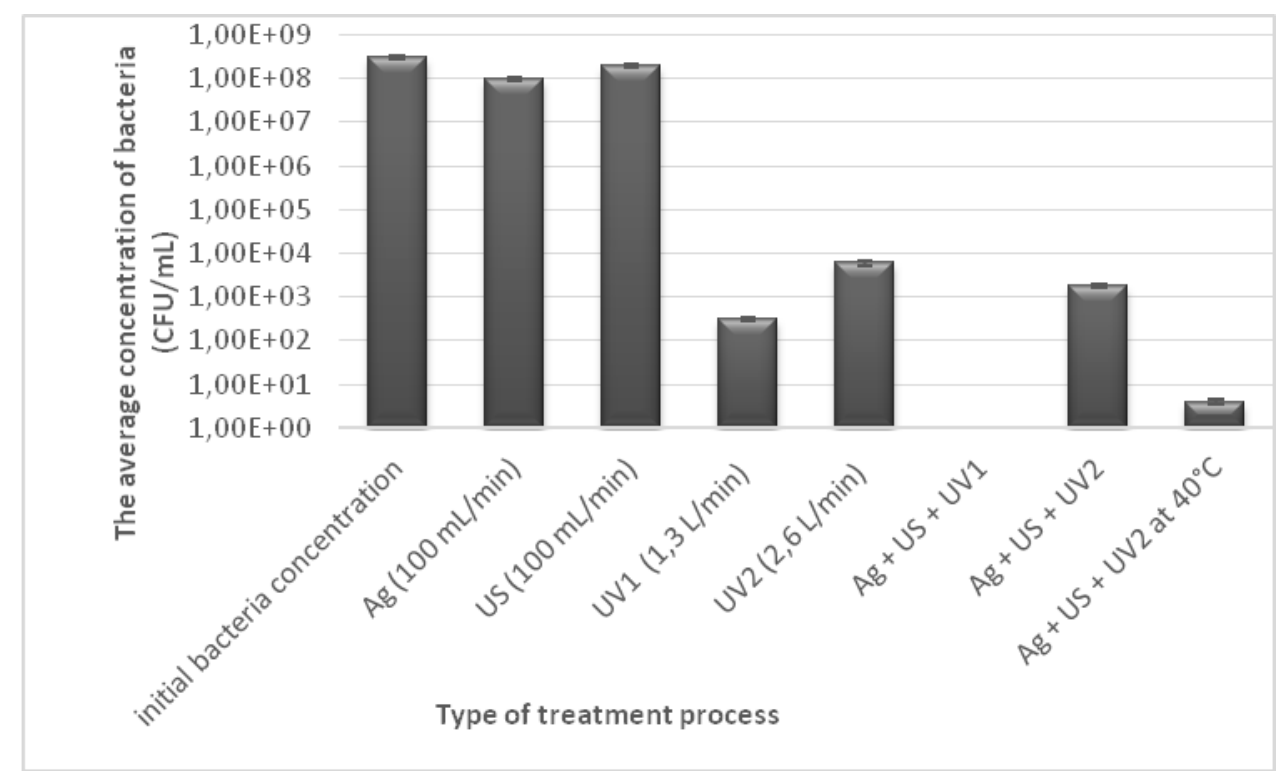

Figure 8. The triple successive effect of the antibacterial filled column, UV reactor and ultrasonic system at a $5 \times 10^{8} \mathrm{CFU} / \mathrm{mL}$ initial bacterial concentration

Table 1. Post hoc statistic test of the triple successive effect of the antibacterial filled column, UV reactor and ultrasonic system at a $5 \times 10^{8}$ CFU/mL initial bacterial concentration

\section{Anova: one-way}

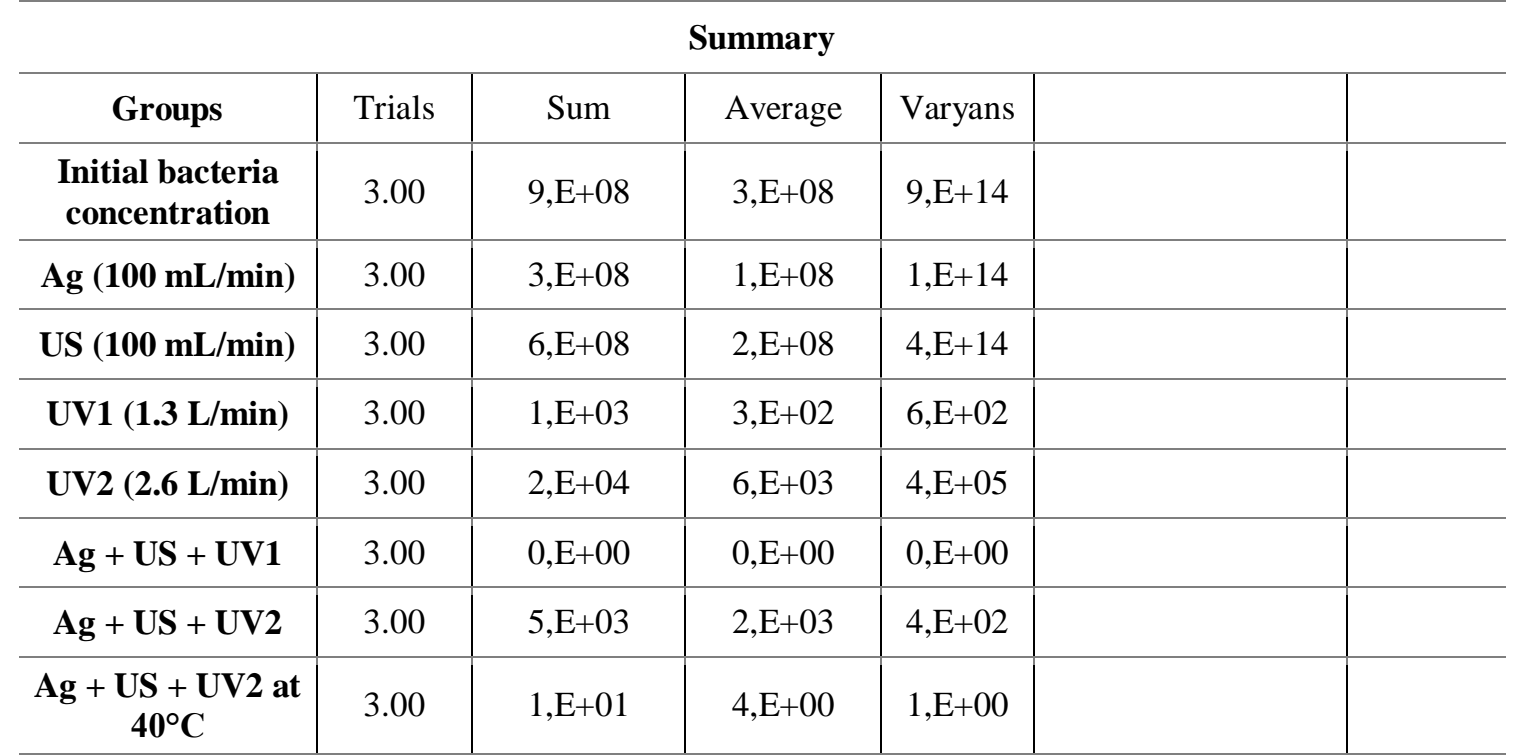

P-value evolution

\begin{tabular}{c|c|c|c|c|c|c}
\hline Varyans resource & SS & df & MS & F & P-value & F criteria \\
\hline Among groups & $3, \mathrm{E}+17$ & 7.00 & $4.07 \mathrm{E}+16$ & 2.32 & 0.00000000000001 & 2.66 \\
\hline In-groups & $3, \mathrm{E}+15$ & 16.00 & $1.75 \mathrm{E}+14$ & & & \\
\hline Total & $3, \mathrm{E}+17$ & 23.00 & & & & \\
\hline
\end{tabular}


The most effective disinfection was achieved in the successive system consisting of the antibacterial filled column, the ultrasonic reactor and the UV reactor used together. The triple hybrid system studies were conducted at $40{ }^{\circ} \mathrm{C}$ with the goal of determining the effect of the temperature. Better results were obtained in the studies conducted at $40{ }^{\circ} \mathrm{C}$ with a $2.6 \mathrm{~L} / \mathrm{min}$ flow rate than at $25^{\circ} \mathrm{C} .2 \mathrm{log}$ inactivation increases was observed with the increase in temperature. $8 \mathrm{log}$ bacterial inactivation was achieved by the triple hybrid system. It was determined that the triple hybrid system showed a synergetic effect.

When triple hybrid studies were conducted using the antibacterial filled column, the ultrasound reactor and the UV reactor together, the disinfection efficiency of Escherichia coli was $8 \log$ after disinfection period. This indicates that Escherichia coli disinfection with triple hybrid studies was performed reducing separate disadvantages of single application of three systems. Although mechanical effects of low-frequency ultrasound were insufficient for disinfection in single treatment, it improved other antibacterial column efficiency with cavitation mass transfer effects of silver ion from filling material surface to bacterial cell membrane. When ultrasound used with UV in successive or triple hybrid system, ultrasound prohibited regrowth of bacteria, which is most common problem in UV treatment, due to mechanical effect on cell membrane. In successive and triple application with antibacterial column, it improved the disinfection efficiency of UV treatment for water samples with high turbidity characteristic. These results indicated that using successive and triple hybrid system application of antibacterial column, UV and ultrasound vanish individual disadvantages of single application of three systems. Temperature effect accelerated the disinfection efficiency for strength microorganisms presented in water to obtain eligible inactivation ratio additionally.

This study was successfully indicated that innovative successive and hybrid disinfection process conducted with silver, ultrasound and UV can be used in order to escape serious problems when faced their single usage.

\section{Conclusion}

In this paper, the targeted Escherichia coli disinfection efficiency was obtained using successive and triple hybrid application of antibacterial column, ultrasound and UV aiming more sufficient inactivation ratio using lower individual disadvantages of these three treatment methods. The highest Escherichia coli inactivation ratio was determined in UV in single treatment application and ultrasound was insufficient for Escherichia coli disinfection due to week mechanical effect of cavitation. The result of successive studies demonstrated that UV, ultrasound and silver ion created synergy to achieve adequate water disinfection efficiency. Increasing disinfection efficiency with successive or triple hybrid systems was expected results but single treatment process of both antibacterial column, ultrasound and UV indicated that synergic effect was not only formed of ultrasound. The hybrid disinfection using antibacterial column, ultrasound and UV provided higher bacterial inactivation efficiency in shorter disinfection period than single processes of these treatment methods, especially when need to more powerful disinfection efficiency for strength microorganisms assisting temperature effect. This study demonstrated that hybrid application of antibacterial column, ultrasound and UV could be performed effectively for water disinfection with less environmental risks and reducing individual disadvantages of disinfection methods. 
Acknowledgements. This study was supported within the scope of the TUBITAK Project No 108 Y019 under the title of "Application of Hybrid Water Disinfection System Application with Nano technologic Material Additive".

\section{REFERENCES}

[1] Abd-Elmaksoud, S., Naranjo, J. E., Gerba, C. P. (2013): Assessment of a portable handheld UV light device for the disinfection of viruses and bacteria in water. - Food and Environmental Virology 5(2): 87-90.

[2] Amirsardari, Y., Yu, Q., Williams, P. (2001): Effect of ozonation and UV irradiation with direct filtration on disinfection and disinfection by-product precursors in drinking water treatment. - Environmental Technology 22(9): 1015-1023.

[3] Bergmann, H., Iourtchouk, T., Schops, K., Bouzek, K. (2002): New UV irradiation and direct electrolysis - promising methods for water disinfection. - Chemical Engineering Journal 85(2-3): 111-117.

[4] Birkin, P. R., Power, J. F., Leighton, T. G. (2001): Electrochemical evidence of H center dot produced by ultrasound. - Chemical Communications (21): 2230-2231.

[5] Blanc, D. S., Carrara, P., Zanetti, G., Francoli, P. (2005): Water disinfection with ozone, copper and silver ions, and temperature increase to control Legionella: seven years of experience in a university teaching hospital. - Journal of Hospital Infection 60(1): 69-72.

[6] Butkus, M. A., Talbot, M., Labare, M. P. (2005): Feasibility of the silver-UV process for drinking water disinfection. - Water Research 39(20): 4925-4932.

[7] Cerecedo, L. M., Dopazo, C., Gomez-Lus, R. (2018): Water disinfection by hydrodynamic cavitation in a rotor-stator device. - Ultrasonics Sonochemistry 48: 71-78.

[8] Chang, Q. Y., He, H., Ma, Z. C. (2008): Efficient disinfection of Escherichia coli in water by silver loaded alumina. - Journal of Inorganic Biochemistry 102(9): 1736-1742.

[9] Choi, Y., Choi, Y. J. (2010): The effects of UV disinfection on drinking water quality in distribution systems. - Water Research 44(1): 115-122.

[10] Copperwhite, R., McDonagh, C., O'Driscoll, S. (2012): A Camera Phone-Based UVDosimeter for Monitoring the Solar Disinfection (SODIS) of Water. - IEEE Sensors Journal 12(5): 1425-1426.

[11] Das, S. K., Khan, M. M. R., Parandhaman, T., Laffir, F., Guha, A. K., Sekarana, G., Mandal, A. B. (2013): Nano-silica fabricated with silver nanoparticles: antifouling adsorbent for efficient dye removal, effective water disinfection and biofouling control. Nanoscale 5(12): 5549-5560.

[12] De Gusseme, B., Hennebel, T., Christiaens, E., Saveyn, H., Verbeken, K., Fitts, J. P., Boon, N., Verstraete, W. (2011): Virus disinfection in water by biogenic silver immobilized in polyvinylidene fluoride membranes. - Water Research 45(4): 1856-1864.

[13] Declerck, P., Vanysacker, L., Hulsmans, A., Lambert, N., Liers, S., Ollevier, F. (2010): Evaluation of power ultrasound for disinfection of both Legionella pneumophila and its environmental host Acanthamoeba castellanii. - Water Research 44(3): 703-710.

[14] Fauss, E. K., MacCuspie, R. I., Oyanedel-Craver, V., Smith, J. A., Swami, N. S. (2014): Disinfection action of electrostatic versus steric-stabilized silver nanoparticles on E. coli under different water chemistries. - Colloids and Surfaces B-Biointerfaces 113: 77-84.

[15] Joyce, E., Phull, S., Lorimer, J., Mason, T. (2003): The development and evaluation of ultrasound for the treatment of bacterial suspensions. A study of frequency, power and sonication time on cultured Bacillus species. - Ultrasonics sonochemistry 10(6): 315-318.

[16] Leighton, T. G. (2007): What is ultrasound? - Progress in Biophysics \& Molecular Biology 93(1-3): 3-83.

[17] Liviac, D., Wagner, E. D., Mitch, W. A., Altonji, M. J., Plewa, M. J. (2010): Genotoxicity of water concentrates from recreational pools after various disinfection methods. - Environmental Science \& Technology 44(9): 3527-3532. 
[18] Marambio-Jones, C., Hoek, E. M. (2010): A review of the antibacterial effects of silver nanomaterials and potential implications for human health and the environment. - Journal of Nanoparticle Research 12(5): 1531-1551.

[19] Mason, T., Joyce, E., Phull, S., Lorimer, J. (2003): Potential uses of ultrasound in the biological decontamination of water. - Ultrasonics Sonochemistry 10(6): 319-323.

[20] Naddeo, V., Landi, M., Belgiorno, V., Napoli, R. M. A. (2009): Wastewater disinfection by combination of ultrasound and ultraviolet irradiation. - Journal of Hazardous Materials 168(2-3): 925-929.

[21] Naddeo, V., Cesaro, A., Mantzavinos, D., Fatta-Kassinos, D., Belgiorno, V. (2014): Water and wastewater disinfection by ultrasound irradiation - a critical review. - Global Nest Journal 16(3): 561-577.

[22] Nelson, K. Y., McMartin, D. W., Yost, C. K., Runtz, K. J., Ono, T. (2013): Point-of-use water disinfection using UV light-emitting diodes to reduce bacterial contamination. Environmental Science and Pollution Research 20(8): 5441-5448.

[23] Oguma, K., Kita, R., Sakai, H., Murakami, M., Takizawa, S. (2013): Application of UV light emitting diodes to batch and flow-through water disinfection systems. Desalination 328: 24-30.

[24] Panyala, N. R., Peña-Méndez, E. M., Havel, J. (2008): Silver or silver nanoparticles: a hazardous threat to the environment and human health? - Journal of Applied Biomedicine (De Gruyter Open) 6(3): 117-129.

[25] Rincon, A. G., Pulgarin, C. (2004): Field solar E-coli inactivation in the absence and presence of TiO2: is UV solar dose an appropriate parameter for standardization of water solar disinfection? - Solar Energy 77(5): 635-648.

[26] Rutala, W. A., Gergen, M. F., Weber, D. J. (2007): Disinfection of a probe used in ultrasound-guided prostate biopsy. - Infection Control and Hospital Epidemiology 28(8): 916-919.

[27] Skauen, D. (1976): A comparison of heat production and cavitational intensity in several ultrasonic cell disrupters. - Ultrasonics 14: 173-176.

[28] Srinivasan, N. R., Shankar, P. A., Bandyopadhyaya, R. (2013): Plasma treated activated carbon impregnated with silver nanoparticles for improved antibacterial effect in water disinfection. - Carbon 57: 1-10.

[29] Summerfelt, S. T., Sharrer, M. J., Tsukuda, S. M., Gearheart, M. (2009): Process requirements for achieving full-flow disinfection of recirculating water using ozonation and UV irradiation. - Aquacultural Engineering 40(1): 17-27.

[30] Vasilyak, L. M. (2010): Ultrasound application in systems for the disinfection of water. Surface Engineering and Applied Electrochemistry 46(5): 489-493.

[31] Winward, G. P., Avery, L. M., Stephenson, T., Jefferson, B. (2008): Ultraviolet (UV) disinfection of grey water: Particle size effects. - Environmental Technology 29(2): 235244.

[32] Wu, D. H., You, H., Zhang, R., Chen, C., Du, J. X. (2011): Inactivation of Escherichia coli using UV/Ag-TiO2/O-3-mediated advanced oxidation: application to ballast water disinfection. - Journal of Chemical Technology and Biotechnology 86(12): 1521-1526.

[33] Xu, B. B., Chen, Z. L., Qi, F., Ma, J., Wu, F. C. (2009): Rapid degradation of new disinfection by-products in drinking water by UV irradiation: N-Nitrosopyrrolidine and N-nitrosopiperidine. - Separation and Purification Technology 69(1): 126-133.

[34] Zhu, Y., Wang, H. B., Li, X. X., Hu, C., Yang, M., Qu, J. H. (2014): Characterization of biofilm and corrosion of cast iron pipes in drinking water distribution system with UV/Cl-2 disinfection. - Water Research 60: 174-181. 